\title{
Th. W. Adorno y la praxis necesaria. Prolegómenos a una propuesta de ética negativa
}

\author{
José A. Zamora
}

Resumen

En la búsqueda de una ética para nuestro tiempo, el autor acude a la obra de Adorno para examinar la relación dialéctica entre praxis y teoría, y afirma que el nuevo concepto de praxis que emerge de esta relación podría guiarnos en la construcción de una ética más crítica que la mayoría demorales, constituidas únicamente por un sistema de normas. El autor defiende la concepción adorniana sobre el lugar del sujeto en la sociedad, que pretende despertar en este sujeto la conciencia de sus capacidades, pero también de sus límites y sobre todo de su falta de libertad; lo que permite a Adorno conceder validez al intento de vida justa del sujeto moderno sólo en su problematicidad y fragilidad.

Palabras clave: ética, teoría, praxis, revolución, M arx, Adorno, Auschwitz.

Abstract. Th. W. Adorno and the necessary Praxis. Prolegomena to a negative Ethics

In the search after an ethics for our time, the author goes to Adorno's work to examine the dialectic relationsship between praxis and theory, and asserts that this new concept of praxis can lead us to an ethics, which would be more critical than the majority of morals, constituted only by a system of norms. The author agrees with Adorno's conception about the place of the subject in the society, which pretends to make this subject conscious of his capacities, but also of his limits and his lack of freedom. It allows Adorno to give validity to the intent of right life of the modern subject only in his problenlaticity and fragility.

Key words: ethics, theory, praxis, revolution, M arx, Adorno, Auschwitz.

El crecimiento apabullante de las publicaciones de ética en los últimos años es interpretado por algunos como signo evidente del aumento de relevancia social de la misma. En cualquier caso, sí que podría ser considerado como un índice de la agudización que ha sufrido la problematicidad de las cuestiones de que trata la filosofía moral. Todo parece indicar quela reflexión ética viene demandada por una necesidad urgente y perentoria de orientación, difícil de determinar en detalle, pero que hunde sus raíces en la pérdida de referentes a 
que la ha abocado la modernidad tardía. Q uizás la pérdida más significativa vendría propiciada por el hundimiento de las filosofías de la historia y de los modelos de praxis que encontraban en ellas su horizonte legitimador.

No cabe duda que el vacío generado por esta pérdida ha hecho florecer un mercado de propuestas éticas y multiplicarse los debates en torno a las mismas de modo inusitado. Pero precisamente este florecimiento hace más necesaria que nunca una reflexión crítica que distinga entre las propuestas valiosas y las espurias, que llame la atención sobre las recaídas del discurso ético por detrás del nivel ya al canzado en los hitos más representativos de su larga historia y que ayude aś a centrar el debate sobre las cuestiones verdaderamente decisivas. D icha reflexión tendrá, pues, que actualizar y reapropiarse las aportaciones más significativas dentro de ese discurso y reexaminar al ternativas aparentemente excluyentes, que más que tener un fundamento objetivo, responden a alineamientos escolásticos escasamente productivos.

En este contexto se sitúan la siguientes reflexiones en torno al concepto de praxis en Th. W. Adorno, cuya aportación a la filosofía moral ha tenido que ser sacada a la luz con un esfuerzo adicional ${ }^{1}$ contra las interpretaciones dominantes de su pensamiento, que suelen asimilarlo al de $\mathrm{H}$ eidegger en la carencia de una ética². La contribución de ese concepto al discurso ético proviene de su fuerza crítica ante la frecuente asimilación de la moral a un entramado de normas que obligan individualmente. Al presuponer lo que en realidad estaría necesitado de prueba: la existencia de un sujeto capacitado para realizar una vida moral dentro del contexto social en cuestión, dicha asimilación incapacita para percibir la impotencia y la fragilidad de lo moral frente a las fuerzas sociales destructivas. Así pues, el concepto adorniano de praxis ayuda a dotar de contornos precisos al ambito en el que hoy se plantea la cuestión moral y a perforar los rígidos límites de la filosofía práctica.

Adorno se enfrentó repetidamente a lo largo de su trayectoria intelectual con la famosa T esis 11 sobre Feuerbach de K. M arx, de que ya no se trata de interpretar el mundo, sino de tranformarlo. D e modo general se puede decir que, ante las nuevas circunstancias históricas que le tocaron vivir, Adorno constataba la desaparición de una posibilidad de transformación revolucionaria de la socie

1. A ello han contribuido diversas publicaciones de las que quisiera resaltar sólo algunas: $\mathrm{H}$. BRUN KH ORST: «V om richtigen Leben im falschen», en: M. LUTZ-BACH M AN N, G. SCH M ID N O ERR (eds.): D ieU nnatürlichkeit der $N$ atur. Ü be Sozialitat der $N$ atur und die $N$ atürlichkeit des Sozialen. Fráncfort del M eno, 1991, p. 146 s.; M. W ISCH KE: Kritik der Ethik des G ehorsams. Z um M oralproblem bei Theodor W. Adorno. Fráncfort del M eno y otros, 1993; G. SCH WEPPEN H ÄU SER: Ethik nach Auschwitz. Adorno's negativeM oral philosophie. H amburgo, 1993; U. KOH LM AN N: «Selbstreflexion der Ethik. H istorisch-systematische Bezugspunkte der M oral philosohie Adornos», en: Zeitschrift für kritischeT heorie2 (1996), p. 89 s.; G . SCH WEPPEN H ÄUSER Y M. W ISCH KE (eds.): I mpuls und N egativität. Ethik und Asthetik bei Adorno. H amburgo/Berlín, 1995. T ampoco habría que olvidar la edición de las clases dadas por Adorno en el semestre de verano de 1963, Th.W. Adorno: Probleme der M oralphilosophie. Th. SCHRÖDER (ed.). Fráncfort del M eno, 1996.

2. Cfr., p.ej., H. SCHNAD ELBACH: Zur Rehabilitierung des animal rationale. Vortrage und Abhandlungen 2. Fráncfort del M eno, 1992, p. 312. 
dad, posibilidad que estaba en la base de dicha tesis y que $M$ arx aún pudo presuponer: «El proletariado, al que él se dirigió», escribe Adorno, «todavía no estaba integrado. Su depauperación aumentaba cada día, mientras que por otra parte el poder social aún no disponía de medios con los que imponerse con toda probabilidad en caso de peligro. La filosofía, en cuanto pensamiento consecuente y libre a la vez, se encuentra en una situación completamente distinta» (Adorno: 1977b, 469). Si en la época burguesa, la ideología de tipo teórico y la praxis opositora se encontraban en una confrontación directa, en el capitalismo tardío, por el contrario, el mismo carácter inevitable y fatal de la pra xis social bajo su figura de dominación técnica de la naturaleza y de intercambio capitalista se ha convertido en una ideología, contra la que nada puede hacer una praxis carente de concepto ${ }^{3}$.

Aunque, naturalmente, tampoco $\mathrm{M}$ arx había enfrentado simplemente la praxis con la teoría, sino que más bien intentó, con ayuda de la crítica de las ideologías, desenmascarar el concepto de espíritu del ideal ismo como la praxis inconsciente de sí misma de una sociedad concreta, la burguesa. D icha praxis, en cuanto reproducción social y material de la vida, estaba ciertamente substraída a la determinación libre de los hombres, lo que equival ea decir que se trataba de una praxis que no hacía justicia a su concepto.

Praxis en sentido enfático, praxis revolucionaria, es decir, en cuanto realización de la autodeterminación racional de los sujetos de la misma, se vuelve contra una praxis llevada a cabo como acción pseudonatural de sujetos sin libertad bajo relaciones de producción capitalistas. «EI telos de la praxis necesaria [según M arx] era la eliminación de su primado bajo la figura de la misma que había dominado completamente la sociedad burguesa» (Adorno: 1973, 242).

Y del mismo modo que la exigencia de $M$ arx de real izar la filosofía a través de la praxis se apoyaba en un análisis teórico de la sociedad y de la historia y no era expresión de un mal decisionismo, así también exige Adorno inflexiblemente una teoría adecuada a la nueva situación, que reflexione además sobre las omisiones de la antigua teoría: «Aquello que permaneció siendo insuficiente

3. C fr. Ad ORn o: 1977a, 23 s. Adorno no convierte el dominio de la naturaleza y la interacción social en dos principios de la praxis igualmente originarios y separados (J. H abermas), sino que los considera momentos dialécticos de un proceso social en movimiento (para una metacrítica de la crítica del concepto de praxis de Adorno llevada a cabo por la teoría comunicativa, cfr. SCH LÜTER: «Praxisverzicht und K ritik der Praxis», en: F. H AGER y H. PFüTZE (eds.): D as unerhört M oderne. Berliner Adorno-T agung. Lüneburg, 1990, p. 64 s.). Por tanto, Adorno intenta comprender la estabilización de la sociedad antagonista desde un concepto dialéctico de la misma. N o es necesario repetir aquí los conocidos argumentos que sirven de base a la discutida teo ría adorniana de la estabilización de la sociedad antagonista. Pero difícilmente se puede rebatir que Adorno no tenía a la vista ningún movimiento político capaz de una revolución mundial de las relaciones de producción. N o sólo faltaban las condiciones sociales de una praxis digna del ser humano, sino que tampoco se podía constatar una praxis revolucionaria que pudiera establecer dichas condiciones. Respecto al juicio de Adorno sobre los movimientos de protesta de los años sesenta, cfr. TÜRCKE: «Praxis und Praxisverweigerung», en: F. H AGER y H. PFütZe (eds.): op. cit., 48-62. 
desde el punto de vista teórico en $\mathrm{H}$ egel y M arx se contagió a la praxis histórica; por ello hay que reflexionar de nuevo teóricamente, en vez de que el pensamiento se someta de modo irracional al primado de la praxis. Ella misma era un concepto eminentemente teórico» (Adorno: 1973, 147).

Sin embargo, Adorno sería el último en defender una autarquía de la teoría. M ás bien se resiste a toda hipostatización, es decir, no sólo a la hipostatización de la teoría, sino también a la de la praxis, y ve en todo intento de reducir un polo al otro o de producir una unidad que ignore la tensión real entre ambas, un signo evidente de una recaída en la filosofía del origen o prima philosophia. D e lo que se trata es de tomar en consideración tanto la mediación mutua como su irreductibilidad. $\mathrm{N}$ i la teoría puede obligar a la praxis a una identidad con ella, ni la praxis debe degenerar en decisionismo (cfr. Adorno: 1977b, 550): «H abría que establecer una conciencia de teoría y praxis que ni las separe de tal modo que la teoría se vuelva impotente y la praxis arbitraria, ni tampoco quebrante la teoría por medio de primado protoburgués de la razón práctica proclamado por Kant y Fichte. El pensamiento es un hacer, la teoría es una figura de la praxis; sólo la ideología de la pureza del pensamiento engaña a este respecto» (Adorno: 1977b, 761).

No obstante, que la teoría sea una figura de la praxis no significa que la teoría pueda sustituir a la praxis - aunque fuera sólo de modo provisionaly mucho menos que deba hacerlo; significa ante todo que la praxis está mediada teóricamente desde el comienzo. El pensamiento es tanto condición de la praxis como producto abstraído de la praxis social. T ener que decidir sobre el primado de la teoría o de la praxis se parece, por tanto, a la conocida pregunta por el huevo o la gallina.

La praxis, en cuanto reproducción de la vida y sus condiciones está siempre mediada por la reflexión, y la reflexión es una dimensión de la praxis social, tanto en su aspecto de dominación de la naturaleza como en el de acción social. D el mismo modo que la historia y la sociedad se han desarrollado hasta el día de hoy bajo condiciones pseudonaturales, así tampoco queda sin consecuencias para la praxis y la teoría la pérdida de experiencia que acompaña a dicho desarrollo.

De modo que la praxis ciega propia de la dominación y la razón cosificada se corresponden. Por ello, la praxis que necesitamos, aquélla que respondiera verdaderamente a la idea de libertad, se encuentra obstruida (cfr. Adorno: $1973,243 ; 228)$. Y si no se reflexiona también sobre la obstrucción que sufre la praxis, se corre el peligro de favorecer por medio del primado de la misma el programa protoburgués de dominación absoluta de la naturaleza bajo el principio de intercambio (C fr. Adorno: 1973, 242).

Con ello no se está proclamando una imposibilidad de principio para la praxis. La crítica de Adorno al primado no dialéctico de la praxis sí que es dia léctica, porque no se vuelca simplemente al otro extremo, sino que sigue afirmando que «sólo es posible escapar al hechizo que la praxis ha colgado sobre el hombre por medio de la praxis, aunque por ahora ésta, insensible, torpe y ale jada del espíritu, coadyuva a fortalecer el hechizo» (Adorno: 1977b, 763). Así 
pues, Adorno no reifica una imposibilidad de la praxis en cuanto tal, sino que critica determinadas formas de la misma y saca a la luz su implicación en el hechizo al que está sometida la sociedad. Por ello, la crítica teórica de la praxis falsa no puede creerse superior a ella, sino que reconoce en la debilidad de la pra xis la suya propia: «La praxis es aplazada y no puede esperar, de ello se resiente también la teoría» (Adorno: 1973, 242).

Q ue la praxis que necesitamos se encuentre obstruida, tan sólo concede paradójicamente «el respiro para pensar que no utilizarlo sería una perversidad» (Adorno: 1973, 243). Ú nicamente como respiro, es la teoría lugarteniente de la libertad en medio de la falta de ella. Pero la reflexión teórica no debe fetichizarse a sí misma autosatisfactoriamente. Tan sólo tiene sentido como crítica de la praxis falsa y como desvelamiento de aquella figura más ele vada de praxis posible que hoy está obstruida. Por mor de la praxis no podemos renunciar pues a la teoría, pues una «praxis sin teoría, es decir, por debajo del estado más avanzado del conocimiento, ha de fracasar necesariamente [...]» (Adorno: 1977b, 766).

Adorno sitúa, además, la dialéctica actual entre teoría y praxis en un horizonte histórico concreto. Es el horizonte de aquellos acontecimientos en los que se nos presenta la recaída moderna en la barbarie: $\mathrm{H}$ iroshima y Auschwitz. Por ello, en relación con ese horizonte, la praxis necesaria se define como «el esfuerzo por sal ir de la barbarie» (Adorno: 1977b, 769). Esta determinación histórica confronta a la praxis con aporías insoslayables como, p. ej., la que existe entre la renuncia a la violencia y la impotencia de la no-violencia, entre el reformismo y la revolución radical, entre la espontaneidad y la organización, etc. Si, por un lado, la victoria sobre el fascismo sólo fue posible con el empleo de la violencia, por otro, una praxis con sentido sólo es imaginable como praxis no-violenta (cfr. Adorno: 1986, 406). Si bien una praxis en sentido enfático está referida a la estructura global de la sociedad, precisamente entonces, si pretende un cambio radical de esa estructura, quedan más patentes las dificultades de una transformación de la misma y crece el peligro de caer en un quietismo cínico 0 desesperado. En relación con estas aporías, Adorno no adopta ninguna actitud rígida, sino que se esfuerza por llevar hasta el final su dialéctica interna. Un aná lisis sin componendas de la tendencia global de la sociedad, la nítida visión de la ausencia de posibilidades de revolucionarla, no significa despreciar lo posible: «Sería una abstracción mala eidealista quitarle importancia o incluso acentuar negativamentela posibilidad de mejoras en el marco de la situación existente en aras de la estructura de la totalidad. Se estaría utilizando un concepto de totalidad que ignora por completo los intereses de los seres humanos vivientes aquí y ahora, lo cual implica un tipo de confianza abstracta en el rumbo de la historia universal, que yo, al menos en esta forma, decididamente no puedo aceptar. Yo diría que cuanto más tenga la estructura social actual [...] el carácter de un bloque sol idificado, de una "segunda naturaleza" incréblemente compacta, que mientras que eso sea así, tal vez las más modestas intervenciones en la realidad existente tienen una significación mucho más grande de lo que por sí mismas les corresponde, casi diría simbólica» (Adorno: 1993, 51 s.). 
Sin embargo, no cabe esperar de la teoría ningunas instrucciones concretas para la praxis. Incluso M arx, que en su 11a tesis sobre F euerbach establecía la praxis como la única razón para la existencia de la teoría, evitó la especificación de toda transición concreta de la crítica de la economía política a la pra xis. « ¿ a relación entreteoría y praxis, una vez que ambas se alejaron mutuamente, es el sal to cualitativo, y no la transición, en ningún caso la subordinación. Las dos se mantienen en una polaridad recíproca» (Adorno: 1977b, 780).

Adorno exige del pensamiento que reflexione sobre su propia falta de libertad, pero también que resista a la coacción de la aplicación práctica a través de la que se impone la praxis instrumental dominante. Sólo así podrá articular sin ambages las aporías a las que se ven expuestos tanto el pensamiento como la praxis, y servir a la praxis que sería necesaria. En esta tarea converge con el arte, en el que Adorno ve tanto el lugarteniente de una praxis mejor, como la crítica de la praxis vigente degenerada en dominio (cfr. Adorno: 1970b, 26). Pero la teoría también necesita de la praxis como su «fuente de energía» (Adorno: 1977b, 782). «En ese sentido, el axioma fichteano de lo moral, que se entiende por sí mismo, mantiene su derecho a pesar de su cuestionabilidad» (Adorno: 1977b, 550).

Así pues, si la praxis verdadera necesita de una conciencia teórica plena, también necesita ésta de algo cualitativamente distinto de ella, de un impulso somático, que no puede crear desde sí misma. La mecha que enciende dicha praxis es el sufrimiento. Por esta razón tiene su telos en la «negación del sufrimiento físico» (Adorno: 1973, 203). La agitación espontánea por la existencia de los campos de concentración y de la tortura no tiene su origen en la razón legisladora, sino en la angustia física y en el sentimiento de solidaridad con los torturados. En cuanto impulso moral, esa agitación espontánea tiene su manifestación en la urgencia y la impaciencia frente a la injusticia, que se resisten a un aplazamiento de la acción por motivos de racionalización o fundamentación. La superación práctica del sufrimiento no tolera ningún aplazamiento.

Pero, por otro lado, la praxis moral no puede prescindir de la conciencia teórica de sus dificultades, es decir, de las razones de por qué el estado global de injusticia cambia tan poco. «La unidad sólo vive en los extremos: en la agitación espontánea que, impaciente con el argumento, no quiere tolerar que el horror siga adelante, y en la conciencia teórica no sometida al terror de ninguna autoridad, que percibe la razón de que esto se mantenga aś indefinidamente. A la vista de la impotencia de todos los individuos, esta contradicción es hoy día el único escenario dela moral» (Adorno: 1973, 281 s.). El hiato entre el impulso espontáneo a la acción solidaria y la reflexión no recortada sobre la destrucción de los potenciales de libertad en el mundo administrado y, con ellos, de las posibilidades de una constitución racional de la sociedad no puede ser restañado, pues viene dado por el estado objetivo actual de la sociedad.

Sin embargo, con esto no se decreta ninguna abstinencia de praxis, sino que se exige ser consciente de la impotencia de todas las acciones reformistas 
ante la magnitud del sufrimiento en el mundo. Lo que no obsta para que dichas acciones comulguen con la praxis verdadera en «cada figura actual de la mitigación de sufrimiento perdurante» y no «sólo en conjurar el descalabro final» (Adorno: 1977b, 630). En la tensión de esos dos polos, Adorno exige pues del sujeto moral una praxis consciente de sus límites y de su complicidad con el statu quo. Haciendo percibir al individuo su falta de libertad, Adorno pretende recordarle la libertad misma, que la filosofía moral le atribuye como una propiedad indefectible, cuando en realidad todavía está por ser alcanzada. « \&a libertad teórica para conocer la propia falta de libertad y la fuerza moral para conocer la limitación de la fuerza para la acción moral crecen en nosotros en la medida en que rompemos el velo ideológico que nos simula la autonomía como un dato libre de duda» 4 .

La famosa frase de Adorno, «no existe ninguna vida justa en medio de lo falso» (Adorno: 1980, 43), a pesar de la impresión que produce de un pesimismo resignado, no defiende en realidad la indiferencia moral a la vista de un estado de oscurecimiento universal sin salida. Esa frase lo que pretende es agudizar la conciencia de que una vida lograda depende de la eliminación de la injusticia en la sociedad y de que sin esa eliminación carece de base. Sólo una ceguera insensible puede engañarse sobre la propia complicidad con la inhumanidad que esta sociedad antihumana necesita para vivir. «El que se cree que, en cuanto producto de esta sociedad, está libre de la frialdad burguesa, al berga ilusiones tanto sobre el mundo como sobre sí mismo; nadie podría ya vivir sin esa frialdad. La capacidad de identificación como el sufrimiento ajeno es en todos sin excepción reducida» (Adorno: 1977b, 778).

Sin embargo, nadie queda dispensado por ello del comportamiento moral ${ }^{5}$. Lo que no se puede es querer simplemente confeccionar normas obligantes, como si éstas pudieran garantizar una vida «justa». Adorno asume aquí la idea de H egel de que «o moral no se entiende de ninguna manera desde sí mismo, de que la conciencia no puede garantizar una acción justa [...]. H egel [...] no opone el bien a la vida empírica como un principio abstracto, como una idea que se basta a sí misma, sino que lo vincula según su propio contenido con el establecimiento de una vida justa - precisamente con aquello que en la Crítica de la razón práctica aparece bajo el nombre de humanidad» (Adorno: 1970a, p. 291). El comportamiento moral se define pues a partir de una doble referencia: a la humanidad realizada y a la autodeterminación del individuo. Esto significa en el estado actual de la sociedad: desde la referencia a la ausencia de ambas. Sin embargo, que la realización de lo moral esté bloqueada en el «mundo administrado» hace que se revalore paradójicamente la significación del individuo. $\mathrm{N}$ o en cuanto enclave libre de contradicciones en un mundo lleno de ellas, sino como adversario de la unanimidad totalitaria. A la vista de una con-

4. G. SCHWEPPENH ÄUSER: Ethik nach Auschwitz. Adorno's negative M oral philosophie H amburgo, 1993, p. 152.

5. Cfr. H. BRUNKH ORST : Theodor W. Adorno. Dialekik der M oderne. M únich/Zurich, 1990, p. $40 \mathrm{~s}$. 
formidad, «que proclama como sentido la eliminación de la diferencia, es posible que algo de la fuerza social liberadora se haya contraído temporalmente a la esfera de lo individual» (Adorno: 1980, 16). El individuo que se opone a la universalidad falsa, por muy débilmente que lo haga, representa de modo utópico la idea de una autonomía y una individualidad, que sólo puede hacerse realidad en una universal idad verdadera como pluralidad realizada y comunicación de lo diferente. O rientarse hacia los individuos, pues, mantiene que cada uno de los individuos ha de querer, sin poder garantizarla, una tal pluralidad y comunicación de lo diferente, incluso deben hacerse responsables de ella, si es que un día ha de ser realidad.

Así pues, la moral no pierde en Adorno el carácter de exigencia, pero sí se corrige la sobreestimación idealista de la pretensión moral. El comportamiento individual puede establecer modelos de vida justa sólo a condición de una conciencia agudizada de su propia precariedad y problematicidad. Sacar a la luz la impotencia de todo intento de vida justa en medio de lo falso significa concederle validez sólo en su fragilidad, problematicidad y en su carácter de suplencia. Pero en cuanto resistencia amenazada contra la inhumanidad existente, contra la pérdida de autonomía del individuo, esos intentos significan también la «última posibilidad de formar células humanas en medio de la universalidad inhumana» (Adorno: 1980, 33).

Sin embargo, ¿cómo es posible fundamentar la resistencia frente a la inhumanidad a la vista del desmoronamiento del individuo? Adorno da a entender que no es posible un aseguramiento teórico de esa resistencia, ya que ésta necesita de un impulso que no puede ser inferido de la conciencia de las normas de comportamiento. «Las cuestiones morales se plantean de modo conciso en frases como: no se debe torturar; no debe haber ningún campo de concentración [...]. Pero si el filósofo moral se apodera de esas frases y exulta de haber pillado al crítico de la moral, porque él también cita los valores procla mados con satiffacción por los filósofos morales, entonces la conclusión lapidaria sería falsa. Verdaderas son esas frases en cuanto impulso, cuando se informa que en algún sitio se ha torturado. Lo que no pueden es racionalizarse; en cuanto principio abstracto caerían en seguida en la mal a infinitud de la deducción y validez» (Adorno 1973, 281).

D e esta manera, Adorno liga la solidaridad humana a la dimensión mimé tica de la experiencia. No es que la reflexión esté de más, como ya hemos visto. Al contrario, aquí no se defiende un espontaneísmo, sino que se aboga por una tensión productiva entre el impulso espontáneo, por un lado, y el comprender reflexivo de la situación inmoral como lugar de la moralidad, por otro. También la moralidad se alimenta esencialmente del estrato corporal del hombre y de su inervación somática contra el sufrimiento, es decir, de algo que hay que añadir a la conciencia. Pero el impulso contra la injusticia causante del sufrimiento no sólo se alimenta de la angustia física y del sentimiento de sol idaridad con los maltratados, sino también del recuerdo del sufrimiento pasa do, como la variante adorniana del imperativo categórico pone de relieve: «H itler ha impuesto a los hombres un nuevo imperativo categórico en el esta- 
do de su falta de libertad: el de disponer su pensamiento y su acción de modo queAuschwitz no se repita, que no vuelva a ocurrir nada semejantes (Adorno: 1973, 358).

En el imperativo categórico kantiano es el sujeto moral el que se da a sí mismo la ley moral por medio de un acto libre. Kant exige para su fundamentación prescindir de todos los impulsos y estímulos empíricos, puesto que la ley moral sólo se ha de apoyar en una razón incondicionada. Si pensamos en todo esto, el imperativo categórico adorniano tiene un tono provocador. Adorno habla de un imperativo «mpuesto». Q uiere desenmascarar a la razón que es autolegisladora y se fundamenta a sí misma como una abstracción. El nuevo imperativo ya no presupone la libertad como existente $y$, a diferencia del kantiano, atribuye a los acontecimientos históricos fuerza imperativa. Sólo si la experiencia histórica y el impulso contra el sufrimiento se unen, es posible pensar en al go así como un imperativo categórico después de la catástrofe de Auschwitz.

Además, la experiencia histórica concreta le imprime a ese imperativo un carácter negativo: formula la exigencia de negación de un estado de cosas. No quiere fundamentar el bien, sino parar el mal o escapar a la barbarie. D e ahí su urgencia y su evidencia. Exigir una fundamentación teórica inatacable de ese imperativo sería en realidad un desafuero, puesto que esa exigencia, a la vista de su trasfondo histórico, se convertiría ella misma en el signo evidente de una destrucción absoluta del sujeto moral, lo que no haría sino documentar la inutilidad de toda fundamentación. Si la necesidad de la eliminación del sufrimiento no fuera evidente, no sería posible ninguna moral en absoluto, pues ésta no es otra cosa que la resistencia contra la inhumanidad. Sólo esta necesidad no inferible concede fuerza al imperativo adorniano.

La oposición contra lo negativo significa al mismo tiempo una caracterización del impulso moral como negativa a colaborar. «La libertad se hace concreta en relación con las figuras cambiantes de la represión: en la oposición contra ellas» (Adorno: 1973, 262). Esto significa resistencia frente a las formas dominantes de praxis, es decir, de la praxis determinada por el principio de producción eintercambio. A este respecto, el arte representa un modelo de praxis verdadera precisamente a través de su negativa a la praxis. El arte no es un sustituto de ella, pero a través de su negativa frente al dominio y la violencia se convierte en una forma de crítica de la praxis dominante. Las obras de arte «oponen su memento contra el prototipo de actividad práctica de hombre práctico, detrás del que se esconde el apetito feroz de la especie, que no será huma nidad mientras que se deje dominar por é y se fusione con el dominio» (Adorno: 1970b, 359).

El arte, como rememoración de la historia del sufrimiento, viene en ayuda de la experiencia plena y sin recortes, sin la que sería imposible una resistencia práctica frente a lo constituido. Y como refugio de la mímesis, conserva el impulso somático-expresivo que está en la base del sentimiento de solidaridad con los sufrientes. Por ello, en medio de la vida falsa, la experiencia estética libera fuerzas que pueden oponerse a la injusticia. «Al enfrentarse las obras de 
arte con las necesidades dominantes, al modificar la iluminación de lo conocido, cosa hacia la que tienden por sí mismas, consiguen responder a la nece sidad objetiva de un cambio de conciencia que podría terminar en un cambio de realidad» (Adorno: 1970b, 361). N o obstante, adolecen de la misma impotencia ante la supremacía del statu quo que los frágiles intentos de una vida justa en medio delo falso. Pero como renuncia a la praxis inmediata, las obras de arte hacen presente la negativa a colaborar e instigan a la resistencia.

\section{O bras citadas de Adorno:}

(1970-1986): G esammelte Schriften. 20 tomos. (Ed.) R. T iedemann. Fráncfort del Meno.

(1970a): Zur M etakritik der Erkenntnistheorie- D rei Studien zu H egel.

(1970b): Ästhetische Theorie.

(1973): N egative Dialektik. Jargon der Eigentlichkeit.

(1977a): Kulturkritik und Gesell schaft 1: Prismen - O hne Leitbild.

(1977b): Kulturkritik und G esell schaft 1: Engriffe - Stichworte- Kritische M odelle 3. (1980): M inima M oralia.

(1986): VermischteSchriften I.

(1993): Einleitung in die Soziologie (1968). (Ed.) Theodor W. Adorno-Archiv. Munich. 